\title{
Estudo do potencial fitotóxico de extratos de Bauhinia ungulata L. sobre a divisão celular e atividade enzimática em plântulas de alface
}

\author{
PAULA, C.S. ${ }^{1 *}$; CANTELI, V.C.D.1; SILVA, C.B.1; MIGUEL, O.G.'; MIGUEL, M.D.1 \\ 'Departamento de Farmácia. Programa de Pós-graduação em Ciências Farmacêuticas. Universidade Federal \\ do Paraná, Av. Pref. Lothário Meissner, 3400, Jardim Botânico, 80210-170, Curitiba, PR, Brasil. *Autor para \\ correspondência: crisspaula@onda.com.br
}

RESUMO: Este trabalho visou avaliar a ação fitotóxica de extrato e frações obtidas das folhas de Bauhinia ungulata $L$ sobre a divisão celular e atividade das enzimas $\alpha$-amilase, catalase, peroxidase e polifenoloxidase em plântulas de alface (Lactuca sativa, var Grand rapis). Sementes de alface foram expostas às concentrações de 250, 500 e $1000 \mu \mathrm{g} . \mathrm{mL}^{-1}$ do extrato de Bauhinia ungulata e frações do mesmo, em condições ambientais controladas. Após três dias de protusão radicular, as raízes das plântulas foram cortadas e submetidas a preparo específico para visualização e contagem do número de células em cada fase mitótica. No sétimo dia, as amostras foram submetidas à avaliação da atividade enzimática utilizando técnica específica para cada enzima e leitura espectrofotométrica. Na análise da divisão celular observou-se que houve redução no número de células em mitose nas raízes das plântulas testadas, e a fração acetato de etila apresentou maior efeito inibitório sobre a divisão celular. O efeito sobre as enzimas que demonstram alterações no sistema de defesa antioxidante de $L$. sativa mostram que o extrato bruto e frações alteraram a produção das enzimas $\alpha$ - amilase, peroxidase, catalase e polifenol oxidase em, ao menos, uma das concentrações testadas, sendo um indicativo de estresse que interfere na divisão celular. Os resultados obtidos apontam para a presença de compostos com atividade inibidora ou estimulatória nas folhas de $B$. ungulata revelando potencial fitotóxico sobre as plântulas de alface.

Palavras-chave: Bauhinia ungulata, catalase, peroxidase.

\begin{abstract}
Study of phytotoxic potential of extracts of Bauhinia ungulata $L$. on cell division and enzyme activity in lettuce seedlings. Theaim of this studywas to evaluate thephytotoxic actionofextractand fractionsobtainedfrom the leaves ofBauhiniaungulata L. inbioassaylaboratory, assessing their interferenceon cell division andactivity of the enzymesalpha-amylase, catalase, peroxidase andpolyphenoloxidaseofLactucasativa(lettu ce). The lettuce seedswere exposedto concentrationsof 250,500 and $1000 \mu \mathrm{g} \cdot \mathrm{mL}^{-10 \text { th }}$ extracts and fractions of Bauhinia ungulataunder controlled environmental conditions. After three days ofrootradicleprotrusion, the plants' rootswere cutand subjected tospecific preparationfor visualization andcounting of the number ofcells in eachmitotic stage. On the seventh daythe sampleswere subjected toenzymatic activityusingspecific techniquefor eachenzyme anda spectrophotometer measure. In the analysisof the mitotic indexit was observedthatthere was reduction in the number of cells in mitosis in the roots of the plants tested and thattheethyl acetate fractionsignificantly affected thecell division. The effecton the enzymesthat showed changesinthe antioxidant defensesystemof Lactucasativaindicate thatthe crude extractand the fractionsaltered theproductionofa-amylase, peroxides, catalaseand polyphenol enzymesin at least oneof the testedconcentrations, representingan indicationstress, which interferesin the celldivision. Theobtained results point out the presence ofcompoundswithinhibitoryorstimulatory activityon plant leaves of $B$. ungulata, revealingphytotoxic potentialtolettuce seedlings.
\end{abstract}

Keywords: Bauhinia ungulata, catalase, peroxidase. 


\section{INTRODUÇÃO}

A Bauhinia ungulata $L$. é uma leguminosa nativa do Brasil conhecida como pata de vaca ou mororó (Maia Neto, 2008) encontrada principalmente nas regiões norte, nordeste, centro-oeste e sudeste. Pouco estudada, a literatura reporta o uso da B. ungulata por índios Tapebas e por parte da população do Ceará, por sua ação hipoglicemiante no tratamento do diabetes (Morais et al., 2005).

Estudos realizados com plantas do gênero Bauhinia mostraram influências destas sobre a germinação e o desenvolvimento das espécies-alvo utilizadas (Mourão Júnior \& Souza Filho, 2010). A fitotoxicidade dos extratos de plantas é atribuída à diversidade de aleloquímicos presentes em sua composição, produtos do metabolismo secundário que atuam inibindo ou favorecendo o processo germinativo bem como o processo de divisão celular, permeabilidade de membranas e na cinética enzimática (Mauli et al. 2009; Pergo \& Ishi Iwamoto, 2011).

Estudos que avaliam o potencial fitotóxico de uma espécie podem fornecer informações iniciais sobre estratégias alternativas para manejo de plantas daninhas, explorando a biodiversidade, com a obtenção de produtos naturais que podem reduzir a dependência aos herbicidas tradicionais. Além de contribuir para o aumento da produtividade agrícola, alguns autores sugerem que estes compostos com atividade fitotóxica podem ser mais seletivos, biodegradáveis e menos poluentes que os herbicidas tradicionais (Macías et al., 2000). Bioensaios preliminares realizados em laboratório avaliando o potencial fitotóxico destes compostos sobre espécies comerciais, como Lactuca sativa (alface), vêm sendo realizados (Trevisan et al., 2012; Paula et al., 2014; Rial et al., 2014; Kato-Noguchi et al., 2014; Wang et al., 2014). As vantagens da utilização da alface nestes; experimentos são a homogeneidade genética, germinação uniforme e fácil disponibilidade, ao contrário das espécies silvestres que são geneticamente mais heterogêneas e apresentam variada sensibilidade, além de falta de homogeneidade na germinação (Macías et al., 2000; Trevisan et al., 2012).

Grande parte dos estudos refere-se apenas ao efeito do aleloquímico sobre a germinação e o crescimento da planta-teste sem levar em consideração eventos celulares ou alterações fisiológicas. Neste contexto, este estudo teve como objetivos verificar a presença de efeito fitotóxico do extrato etanólico e das frações do mesmo, produzidos a partir de folhas de Bauhinia ungulata $\mathrm{L}$. sobre o índice de mitoses em células meristemáticas das raízes e alteração na produção das enzimas alfa amilase, peroxidase, catalase e polifenoloxidase.

\section{MATERIAL E MÉTODOS}

As folhas de Bauhinia ungulata L. foram coletadas em janeiro de 2007 na cidade de Campo Grande - Mato Grosso do Sul, coordenadas geográficas $20^{\circ} 30^{\prime} 37,5^{\prime \prime} \mathrm{S}$ e $54^{\circ} 36^{\prime} 46,6^{\prime \prime} \mathrm{W}, 545 \mathrm{~m}$. A identificação foi realizada por um especialista na área com exsicata depositada no Herbário da Universidade Federal de Mato Grosso do Sul UFMS sob o número CGMS 19754, e autorização do IBAMA para acesso ao Patrimônio Genético no 02001.001165/2013-47.

O material vegetal foi seco em temperatura ambiente e triturado em moinho de facas/martelo. O extrato bruto foi obtido a partir de $1,5 \mathrm{~kg}$ deste material em etanol, com a utilização de aparelho de Sohxlet e posteriormente utilizado para a obtenção das frações por partição líquido/líquido utilizando solventes com polaridade crescente: n-hexano, clorofórmio e acetato de etila. A partir do extrato etanólico bruto (EEB), fração hexano $(\mathrm{FH})$, fração clorofórmio ( $F C L)$, fração acetato de etila (FAE) e fração hidro alcoólica residual (FR), foram realizados os ensaios propostos.

Em placas de petri contendo papel de filtro, foram adicionados $5,0 \mathrm{~mL}$ das soluções EEB e frações preparadas em quadruplicatas nas concentrações de $250 \mu \mathrm{g} \cdot \mathrm{mL}^{-1}, 500 \mu \mathrm{g} \cdot \mathrm{mL}^{-1}$, $1000 \mu \mathrm{g} \cdot \mathrm{mL}^{-1} 5,0 \mathrm{~mL}$, e água destilada em placas identificadas como controle negativo. Na sequência foram adicionadas em cada placa cinquenta sementes de alface (Lactuca sativa cv. Grand Rapids) que permaneceram em contato com a solução durante todo período do experimento assim como as soluções. As placas foram mantidas em câmara de germinação (BOD) em condições de luz $(160 \mathrm{~W})$, umidade relativa $( \pm 80 \%)$ e temperatura constante $\left(25^{\circ} \mathrm{C}\right)$ por sete dias para germinação e crescimento.

No terceiro dia após a protusão radicular, segmentos de dois centímetros a partir da extremidade distal das radículas de três amostras de cada placa foram retirados, e colocadas em $5 \mathrm{~mL}$ de solução de Farmer (3:1 etanol; ácido acético glacial) por 2 horas, a $25^{\circ} \mathrm{C}$, com posterior transferência para uma solução de álcool $70 \%$. Para determinar interferência na divisão celular as pontas das raízes foram tratadas sequencialmente com água destilada por 5 minutos; ácido clorídrico $1 \mathrm{M}$ por 30 minutos, a temperatura ambiente. Em seguida, novo tratamento com água destilada por 5 minutos e orceina acética $2 \%$ por 30 minutos. As pontas das raízes tiveram o ápice, $2,0 \mathrm{~mm}$ iniciais, cortados sobre lâmina de microscópio e pressionando sob lamínula para esmagamento e retirada do excesso de corante. O material foi observado em microscópio óptico comum (aumento

Rev. Bras. PI. Med., Campinas, v.17, n.4, p.577-584, 2015. 
de 1000X) contando-se o número de células em cada fase da mitose (prófase, metáfase, anáfase e telófase). Para cada tratamento, foram preparadas três lâminas, avaliando-se três campos por lâmina. Os resultados são apresentados em porcentagem em relação ao controle, sendo que o zero representa o controle, valores positivos representam estímulo e valores negativos representam inibição de atividade mitótica (Macías et al., 2000).

Para avaliação da atividade enzimática, ao final do período determinado para germinação e crescimento, foi preparado o extrato enzimático. As plântulas foram trituradas com auxílio de nitrogênio líquido com posterior adição de $10 \mathrm{~mL}$ e tampão fosfato de potássio $(0,2 \mathrm{M}, \mathrm{pH} 7)$ e submetidas a centrifugação $\left(2500 \mathrm{rpm}\right.$ por 20 minutos a $4{ }^{\circ} \mathrm{C}$, sendo o sobrenadante coletado e constituindo o extrato enzimático (Putter, 1974). Este extrato enzimático foi mantido em freezer em temperatura de $4^{\circ} \mathrm{C}$, e utilizado para as dosagens das enzimas, conforme metodologias específicas a seguir.

No ensaio de atividade da $\alpha$-amilase, $400 \mu \mathrm{L}$ dos extratos enzimáticos foram adicionados em tubos de ensaio e mantidos em banho-maria $\left(70^{\circ} \mathrm{C}\right.$ durante 20 minutos) (AOAC,1965) com posterior adição de $0,5 \mathrm{~mL}$ de tampão acetato $(1,0 \mathrm{M}, \mathrm{pH} 7)$ e $1,0 \mathrm{~mL}$ de solução de amido a $1 \%$, sendo então incubados a $30^{\circ} \mathrm{C}$ (5 minutos). Após este período, foi adicionado $0,5 \mathrm{~mL}$ de solução de Lugol $50 \%$ e $1 \mathrm{~mL}$ de água destilada, e em seguida, efetuouse a leitura em espectrofotômetro a $620 \mathrm{~nm}$. As absorbâncias foram calculadas segundo a AOAC (1965), segundo a equação:

AT $=[($ substrato a $620 \mathrm{~nm}$ - leitura $620 \mathrm{~nm})$ / $5 \mathrm{~min} \times \mathrm{A})] \times(20 \mathrm{~min} / 0,5 \mathrm{~min} \times 0,5 \mathrm{~g}$ de massa fresca),

em que:

AT = Atividade Total da enzima $\alpha$-amilase; substrato a $620 \mathrm{~nm}=$ controle negativo (tampão acetato, solução de amido a $1 \%$ e solução de lugol a $50 \%$ );

leitura $620 \mathrm{~nm}=$ extrato enzimático (tampão acetato, solução de amido a $1 \%$ e solução de lugol a $50 \%$ e $\mathrm{A}=1 \mu \mathrm{g}$ de amido.

Os dados foram expressos em $\mu \mathrm{g}$ de amido hidrolizado min $^{-1}$ por $\mathrm{g}$ de material fresco-1.

A atividade da peroxidase foi avaliada com adição de $1 \mathrm{~mL}$ de tampão fosfato de potássio $(0,2 \mathrm{M}$; $\mathrm{pH} 7,0)$ a $1 \mathrm{~mL}$ dos extratos enzimáticos, mantidos em banho-maria a $25^{\circ} \mathrm{C}$. Em seguida, adicionou-se $500 \mu \mathrm{L}$ de guaiacol $(0,5 \%)$ e $500 \mu \mathrm{L}$ de peróxido de hidrogênio $(0,08 \%)$, sendo imediatamente realizada a leitura de absorbância a 470 nm (Putter, 1974).

Para o cálculo da atividade enzimática, U.mL-1, foi empregada a equação:

$$
\text { U. } \min ^{-1}=(A / \epsilon) \times(1 / \mathrm{Ve}) \times \mathrm{FD} \times(1 / \mathrm{t}) \times 1000
$$

em que:

U.min-1= unidade de atividade por $\mathrm{mL}$;

A = absorbância;

$\epsilon=$ absortividade molar do tetraguaiacol $(26.600 \mathrm{~mol}$ $\left.{ }^{1} \mathrm{~cm}^{-1}\right)$ ou absortividade do catecol $\left(26.900 \mathrm{~mol}^{-1} \mathrm{~cm}^{-1}\right)$; $V e=$ volume da solução de enzima utilizada no ensaio $(\mathrm{mL})$;

FD = fator de diluição (diluição do extrato bruto enzimático) e;

$\mathrm{t}=$ tempo de reação em minutos

A atividade da catalase foi determinada com adição de $3 \mathrm{~mL}$ de peróxido de hidrogênio (12,5 mM) em água destilada a $100 \mu \mathrm{L}$ de extrato enzimático a $30^{\circ} \mathrm{C}$. A atividade da catalase foi determinada pela medição da redução na absorbância das amostras a $240 \mathrm{~nm}$, em consequência do consumo de $\mathrm{H}_{2} \mathrm{O}_{2}$, usando-se o coeficiente de extinção molar de $36 \mathrm{M}^{-1}$ $\mathrm{cm}^{-1}$ (Anderson et al., 1995) e calculada segundo a fórmula (Bracht et al., 2003):

$$
\text { Atividade da catalase }\left(\mu \mathrm{mol} \min ^{-1}\right)=\frac{\text { vol de incubação } x \alpha \operatorname{tg}\left(\min { }^{-1}\right)=\text { unidades de enzima }}{\text { Coeficiente de extinção molar da enzima }(\varepsilon)}
$$

$(\alpha \operatorname{tg})=\Delta \mathrm{A} / \Delta \mathrm{t} ;$ sendo:

$\alpha \operatorname{tg}=$ variação da tangente

$\Delta \mathrm{A}=$ a variação da absorbância $\mathrm{e}$

$\Delta t=a$ variação do tempo (minutos) .

A atividade da polifenoloxidase foi determinada com adição de $1 \mathrm{~mL}$ de tampão fosfato de potássio $(0,05 \mathrm{M}, \mathrm{pH} 6,0)$ e $0,5 \mathrm{~mL}$ de catecol $0,1 \mathrm{M}$, a $1 \mathrm{~mL}$ do extrato enzimático e incubação a $30^{\circ} \mathrm{C}$ (30 minutos) com posterior transferência para um banho de gelo. A esta se adicionou 0,5 $\mathrm{mL}$ de ácido perclórico $1,4 \%$, deixando-se em repouso por 10 minutos e posterior leitura a $395 \mathrm{~nm}$ (Duangmal \& Apenten, 1999). A atividade da enzima polifenoloxidase foi calculada usando a mesma equação para o calculo da atividade da peroxidase, citada anteriormente (Putter, 1974; Duangmal \& Apenten, 1999; Zeraik et al., 2008):

Para cada amostra avaliada, o delineamento experimental foi inteiramente casualizado com 
quatro tratamentos (controle em água destilada e 250,500 e $1000 \mu \mathrm{g} \cdot \mathrm{mL}^{-1}$ das amostras) em três repetições. Os dados foram submetidos à análise de variância e as médias foram comparadas pelo Teste de Tukey a $5 \%$ de probabilidade com auxílio do programa SISVAR. As médias obtidas foram calculadas em porcentual em relação ao controle.

\section{RESULTADOS E DISCUSSÃO}

Os resultados obtidos no experimento que avalia a interferência do extrato e frações sobre a

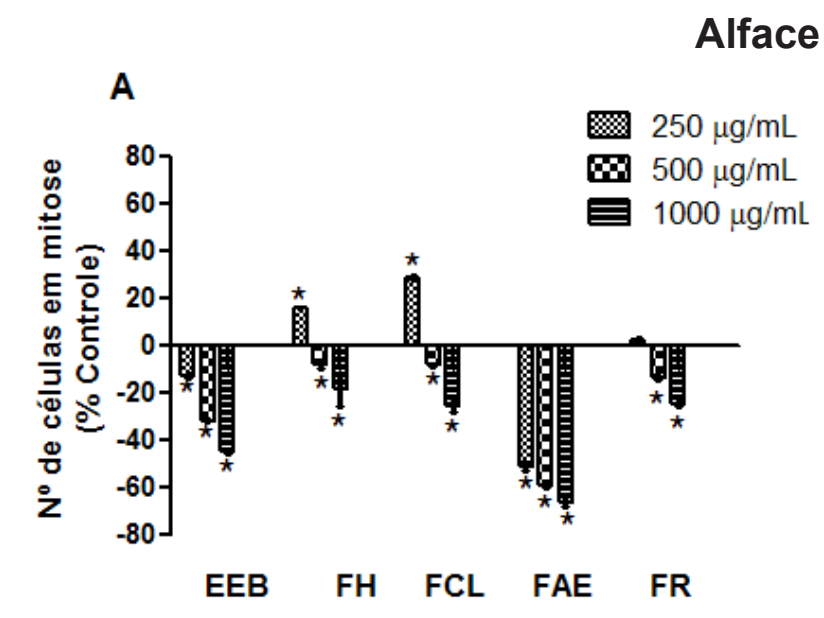

L. sativa $\mathbf{L}$.
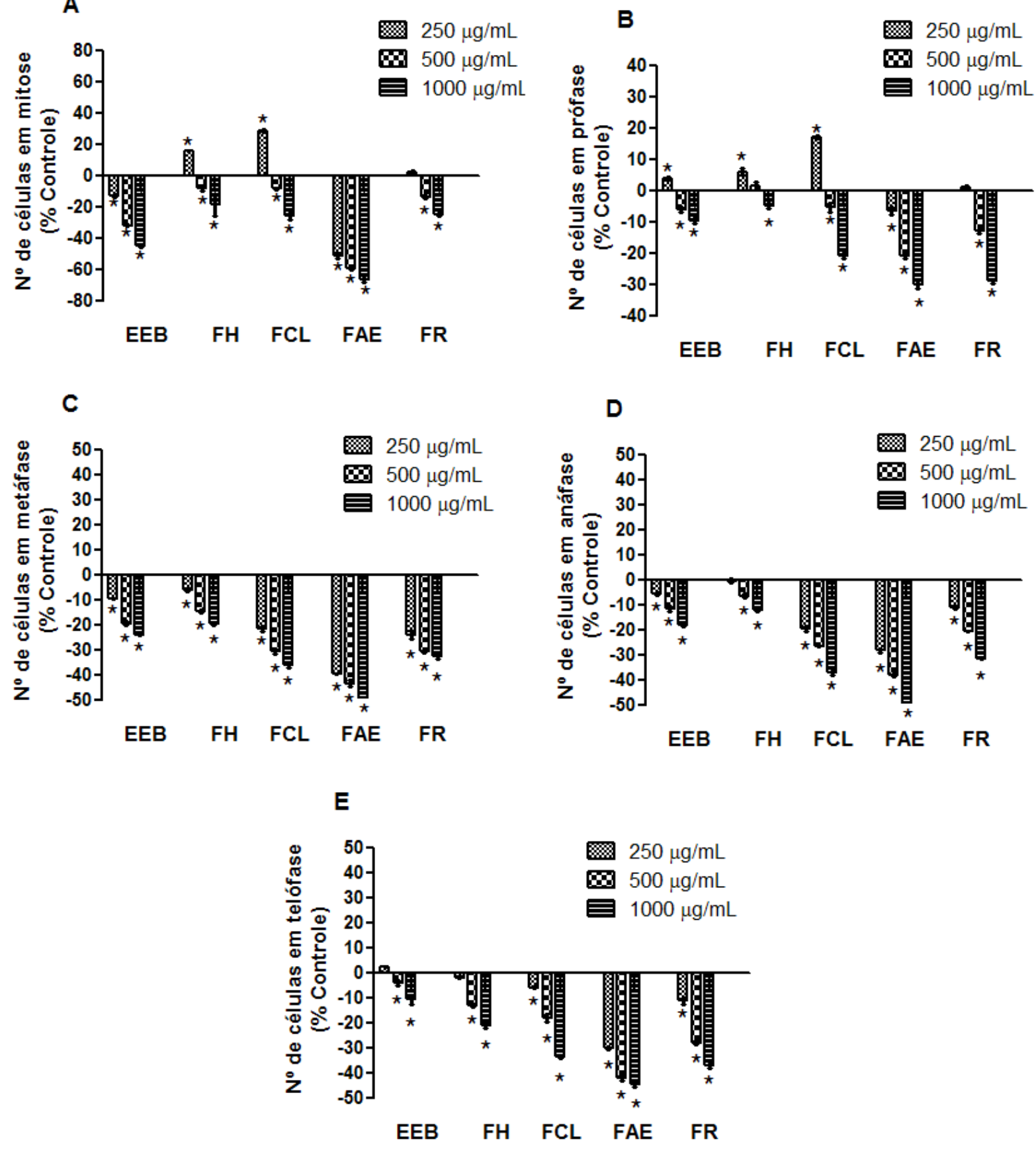

FIGURA 1. Índice mitótico em células meristemáticas de raízes de plântulas de alface, expostas a diferentes concentrações do extrato bruto (EEB), a fração hexânica (FH), clorofórmica (FCL), fração acetato de etila (FAE) e fração hidroalcoólica remanescente (FR) obtidas de Bauhinia ungulata $\mathrm{L}$. Dados expressos em percentual em relação ao controle . *A média do tratamento difere significativamente $(p<0,05)$ em comparação com a média do controle, pelo teste de Tukey. 
divisão celular são ilustrados na Figura 1 A-D. O aumento da concentração do extrato e frações gerou maior ação inibitória sobre a atividade mitótica, sendo mais expressivo sob influência da fração FAE (Figura 1-A).

A fração FAE $\left(1000 \mu \mathrm{g} \cdot \mathrm{mL}^{-1}\right)$ gerou uma taxa de inibição de $51,9 \%$ das células em anáfase (Figura 1-D), 50,1\% em metáfase (Figura 1-C), $44,4 \%$ em telofase (Figura 1-E) e 30,1\% em prófase (Figura 1-B) em relação as células das plântulas do controle. Efeitos estimulatórios foram observados sobre a prófase nas menores concentrações do EEB e frações $\mathrm{FH}, \mathrm{FCL}$ e FR. O predomínio de efeitos inibitórios sobre as diferentes fases da mitose em células meristemáticas nas raízes das plântulas de alface levam a uma diminução no crescimento, tendo em vista que esta região meristemática é a responsável pela produção de novas células e está estreitamente relacionada com o crescimento das raízes (Adam \& El-Ashry, 2010).

Com relação à alterações na divisão celular, foi observado que a concentração de $250 \mu \mathrm{g} / \mathrm{mL}$ da FH e FCL estimularam a divisão celular em raízes de alface. As concentrações de 500 e $1000 \mu \mathrm{g} / \mathrm{mL}$ dessas frações, o EEB, FAE e FR diminuíram o número de células em divisão, sendo que a FAE foi a fração que provocou um maior efeito inibitório quando comparado ao controle (Figura $1 \mathrm{~A}$ ). $\mathrm{O}$ mesmo efeito foi observado nas células em prófase para o EEB, FH e FCL, causando um estímulo nessa fase da divisão celular. As demais frações inibiram o número de células em prófase quando comparadas ao controle, com acentuada atividade para a concentração de $1000 \mu \mathrm{g} / \mathrm{mL}$ da FAE e FR (Figura $1 \mathrm{~B}$ ).

O aumento do número de células em mitose pode ser atribuído à redução da toxicidade e citotoxicidade (González et al., 2011). Por outro lado, alterações na divisão celular observadas principalmente na prófase, podem ser prejudiciais às células, pois podem levar a proliferação celular desordenada e formação de calos em raízes (Leme \& Marin-Morales, 2009).

O EEB e frações reduziram o número de células em metáfase, anáfase e telófase com efeitos inibitórios mais acentuados para a FAE. Efeitos de estímulo não foram observados nessa fase de diferenciação celular (Figura 1 C, D e E). $\mathrm{O}$ crescimento celular depende de um processo normal da mitose (Ding et al., 2010). A divisão uniforme de todos os componentes celulares permite um crescimento equilibrado para o organismo (Reigosa et al., 2006). O controle da progressão do ciclo celular e o número de células em divisão definem o crescimento e morfogenese da planta, e qualquer alteração no tempo e ordem desses eventos, irá atuar como um fator crítico no seu desenvolvimento (Reigosa et al., 2006). Assim, as respostas observadas tanto para estímulo quanto inibição podem estar relacionadas à concentração necessária para causar fitotoxicidade. Neste contexto, Reigosa et al. (1999) relataram que os efeitos dos aleloquímicos nos diferentes processos fisiológicos de uma planta são dependentes da concentração, ou ao menos se espera que sejam, promovendo ativações em baixas concentrações e inibições em altas concentrações.

Os flavonoides quercetina, quercetina-3Oarabinofuranosídio e quercitrina foram isolados das folhas da Bauhinia ungulata (Maia Neto et al., 2008), e a atividade fitotóxica deste grupo de metabólitos secundários já foi reportada na literatura (Melos et al., 2007, Almeida et al., 2008). Assim é esperado que estes flavonoides possam estar presentes na FAE, e desta forma é possível supor que tais efeitos do extrato e frações observados nos experimentos se devam em grande parte a estas substâncias. Estes compostos podem ser responsáveis, isolado ou sinergicamente, pela interferência nos processos fisiológicos durante a fase de desenvolvimento das espécies-alvo em estudo (Einhellig, 1986).

Nos ensaios enzimáticos (Tabela 1), foi observado que os extratos e frações aumentaram o conteúdo de a-amilase em $L$. sativa. O EEB e $\mathrm{FH}$ provocaram considerável aumento na atividade desta enzima quando comparada as demais frações.

Somente a FAE 500 e $1000 \mu \mathrm{g} \cdot \mathrm{mL}^{-1}$ não promoveram aumento da atividade enzimática, apresentando resultados semelhantes ao controle. A a-amilase é uma enzima hidrolítica sintetizada durante as primeiras fases da germinação, responsável pela conversão do amido em açúcares utilizados especialmente para o crescimento da plântula (Carvalho \& Nakagawa, 1988). O aumento da atividade desta enzima pode estar relacionado a um aumento de gasto energético por parte das células para a defesa da espécie alvo frente a um agente agressor (Jacobsen et al., 1986).

$\mathrm{Na}$ avaliação da atividade das peroxidases foram observados estímulo e inibição com as amostras obtidas de $B$. ungulata. As peroxidases são responsáveis pela remoção de átomos de hidrogênio dos grupos álcoois hidroxicinâmicos, cujos radicais se polimerizam para formar a lignina (Viecelli et al., 2010), e estão relacionadas a eventos que envolvem indução de resistência ou adaptação frente a condições adversas que geram estresse (Cavalcanti et al., 2005), ou seja, é uma proteção antioxidativa. Apesar disso, não é observado um comportamento padrão (Cavalcanti et al., 2005), pois depende do tipo de indutor, concentração, tempo após a sua aplicação na planta e patossistema em estudo. Viecelli (2010) também observou redução na atividade de peroxidases em feijoeiro tratado com 
TABELA 1. Atividade enzimática de L. sativa (alface) frente ao extrato bruto etanólico e frações obtidas de folhas de $B$. ungulata $L$.

\begin{tabular}{|c|c|c|c|c|c|c|}
\hline \multicolumn{4}{|c|}{$\begin{array}{l}\text { a-AMILASE ( } \mu \mathrm{g} \text { de amido hidrolizado } \mathrm{min}^{-1} \text { por } \mathrm{g} \text { de material } \\
\text { fresco-1) }\end{array}$} & \multicolumn{3}{|c|}{ PEROXIDASE (U.min-1 ) } \\
\hline Amostra & $250 \mu \mathrm{g} \cdot \mathrm{mL}^{-1}$ & $500 \mu \mathrm{g} \cdot \mathrm{mL}^{-1}$ & $1000 \mu \mathrm{g} \cdot \mathrm{mL}^{-1}$ & $250 \mu \mathrm{g} \cdot \mathrm{mL}^{-1}$ & $500 \mu \mathrm{g} \cdot \mathrm{mL}^{-1}$ & $1000 \mu \mathrm{g} \cdot \mathrm{mL}^{-1}$ \\
\hline EEB & $40,45 \pm 0,77$ k & $34,85 \pm 1,29$ & $31,01 \pm 1,27$ & $0,02 \pm 0,02^{a}$ & $0,02 \pm 0,02^{a}$ & $0,03 \pm 0,02^{a}$ \\
\hline $\mathrm{FH}$ & $28,07 \pm 1,06^{n}$ & $27,85 \pm 1,11^{\mathrm{h}}$ & $25,87 \pm 1,27^{h}$ & $0,23 \pm 0,01^{\mathrm{fg}}$ & $0,16 \pm 0,02^{\mathrm{de}}$ & $0,08 \pm 0,01^{b}$ \\
\hline $\mathrm{FCl}$ & $19,07 \pm 0,26^{\dagger}$ & $22,05 \pm 0,70$ & $10,65 \pm 1,23^{\mathrm{cd}}$ & $0,23 \pm 0,02^{\mathrm{fg}}$ & $0,13 \pm 0,01^{c d}$ & $0,03 \pm 0,006^{a}$ \\
\hline FAE & $14,20 \pm 0,87^{e}$ & $4,93 \pm 0,27^{a}$ & $6,91 \pm 0,50$ ab & $0,12 \pm 0,01^{\mathrm{cd}}$ & $0,02 \pm 0,01^{a}$ & $0,24 \pm 0,01^{g}$ \\
\hline FR & $11,27 \pm 0,60 \mathrm{c}^{d}$ & $8,40 \pm 0,07 \mathrm{bc}$ & $12,87 \pm 1,80^{\text {de }}$ & $0,19 \pm 0,01_{\mathrm{ef}}$ & $0,02 \pm 0,01^{a}$ & $0,11 \pm 0,02^{\mathrm{bc}}$ \\
\hline Controle & $4,13 \pm 0,40 \mathrm{a}$ & $4,13 \pm 0,40^{a}$ & $4,13 \pm 0,40^{a}$ & $0,09 \pm 0,01^{b c}$ & $0,09 \pm 0,01^{\mathrm{bc}}$ & $0,09 \pm 0,01 \mathrm{bc}$ \\
\hline \multicolumn{4}{|c|}{ CATALASE ( $\mu$ mol min-1 $\mathrm{g}^{-1}$ de material fresco) } & \multicolumn{3}{|c|}{ POLIFENOL OXIDASE (U.min-1 ) } \\
\hline Amostra & $250 \mu \mathrm{g} \cdot \mathrm{mL}^{-1}$ & $500 \mu \mathrm{g} \cdot \mathrm{mL}^{-1}$ & $1000 \mu \mathrm{g} \cdot \mathrm{mL}^{-1}$ & $250 \mu \mathrm{g} \cdot \mathrm{mL}^{-1}$ & $500 \mu \mathrm{g} \cdot \mathrm{mL}^{-1}$ & $1000 \mu \mathrm{g} \cdot \mathrm{mL}^{-1}$ \\
\hline EEB & $0,12 \pm 0,01^{\text {cd }}$ & $0,32 \pm 0,04$ & $0,30 \pm 0,02^{f}$ & $5,58 \pm 0,24$ ab & $11,2 \pm 0,43^{\text {fg }}$ & $9,72 \pm 0,21^{\text {def }}$ \\
\hline $\mathrm{FH}$ & $0,25 \pm 0,01_{\text {ef }}$ & $0,15 \pm 0,02^{\text {cde }}$ & $0,15 \pm 0,03^{\text {cde }}$ & $13,15 \pm 1,939$ & $10,74 \pm 1,05^{\text {ef }}$ & $7,99 \pm 0,46^{\text {acd }}$ \\
\hline $\mathrm{FCl}$ & $0,24 \pm 0,07_{\text {ef }}$ & $0,11 \pm 0,02^{\mathrm{cd}}$ & $0,07 \pm 0,04^{\mathrm{bc}}$ & $16,29 \pm 0,15^{h}$ & $8,54 \pm 0,38^{\mathrm{cd}}$ & $8,76 \pm 0,31$ de \\
\hline FAE & $0,01 \pm 0,02^{\mathrm{ab}}$ & $0,11 \pm 0,03^{\text {cd }}$ & $0,16 \pm 0,02^{\text {cde }}$ & $4,86 \pm 0,27$ a & $5,14 \pm 0,10^{a}$ & $9,4 \pm 0,34^{\text {cdef }}$ \\
\hline FR & $0,13 \pm 0,01_{\text {cd }}$ & $0,09 \pm 0,01^{a}$ & $0,14 \pm 0,02^{\mathrm{cd}}$ & $7,32 \pm 1,14 \mathrm{bc}$ & $4,08 \pm 0,222^{a}$ & $4,50 \pm 0,40$ a \\
\hline Controle & $0,18 \pm 0,05^{\mathrm{de}}$ & $0,18 \pm 0,054$ & $0,18 \pm 0,05^{\mathrm{de}}$ & $7,72 \pm 0,71^{\mathrm{cd}}$ & $7,72 \pm 0,71^{\mathrm{cd}}$ & $7,72 \pm 0,71^{\mathrm{cd}}$ \\
\hline
\end{tabular}

Extrato Etanólico Bruto (EEB), fração hexânica $(F H)$, fração clorofórmio (FCl); fração acetato de etila (FAE) e fração hidroalcoólica remanescente $(F R)$. Médias seguidas com a mesma letra na mesma coluna não diferem estatisticamente entre si pelo Teste de Tukey ( $p$ $<0,05)$.

extrato aquoso de Pycnoporus sanguineus a $10 \%$ e inoculado com Pseudocercospora griseola (patógeno causador da Mancha Angular). O mesmo extrato, na concentração de $20 \%$, incrementou a atividade de peroxidases no quarto dia após a inoculação, mas reduziu no quinto e sétimo dias. Esse comportamento oscilante na atividade de peroxidases também foi descrito por Baldo (2008) utilizando esses mesmos extratos aquosos em feijoeiro inoculado com Colletotrichum lindemuthianum. No experimento realizado $\operatorname{com} B$. ungulata registrou-se tanto efeitos estimulatório como inibitórios, dependendo da fração e concentração testada, mas não foi possível verificar se a mesma amostra apresentou os dois comportamentos tendo em vista que a avaliação foi realizada somente no sétimo dia após o inicio do crescimento.

$\mathrm{Na}$ avaliação da atividade da catalase houve estímulo na atividade enzimática sob ação do EEB nas duas maiores concentrações, e inibição com a FAE $250 \mu \mathrm{g} \cdot \mathrm{mL}^{-1}$, FCL $1000 \mu \mathrm{g} \cdot \mathrm{mL}^{-1}$ e FR 500 $\mu \mathrm{g} \cdot \mathrm{mL}^{-1}$. As outras amostras foram estatisticamente semelhantes ao controle. A catalase está envolvida diretamente na remoção do peróxido de hidrogênio (Riedle-Bauer, 2000) e uma atividade aumentada desta enzima, sugere maior proteção e eficiência.

O EEB e frações estimularam a produção da polifenol oxidase em alface, e o EEB (500 $\left.\mu \mathrm{g} \cdot \mathrm{mL}^{-1}\right), \mathrm{FH}\left(250\right.$ e $\left.500 \mu \mathrm{g} \cdot \mathrm{mL}^{-1}\right)$ e FCL $\left(250 \mu \mathrm{g} \cdot \mathrm{mL}^{-1}\right)$ causaram estímulo superior à FAE e FR. Um efeito inibitório foi observado para o EEB $\left(250 \mu \mathrm{g} \cdot \mathrm{mL}^{-1}\right)$, FAE $\left(250\right.$ e $\left.500 \mu \mathrm{g} \cdot \mathrm{mL}^{-1}\right)$, FR $\left(500\right.$ e $\left.1000 \mu \mathrm{g} \cdot \mathrm{mL}^{-1}\right)$. A enzima polifenol oxidase é uma oxido-redutase responsável pela aparência escura de produtos agrícolas descascados e em mecanismos de defesa das plantas, sendo geralmente encontrada em maior atividade em tecidos infectados. A importância da atividade desta enzima na resistência a doenças é provavelmente devido à propriedade de oxidar compostos fenólicos, resultando em altas concentrações de produtos tóxicos de oxidação (Campos et al, 2004).

A produção de EROs pode ser estimulada pelos aleloquímicos por diversos mecanismos, e o aumento destas espécies leva principalmente a um aumento da atividade de peroxidases, catalase e polifenol oxidase, entre outras, provavelmente como defesa da planta contra ação fitotóxica destes compostos (Campos et al., 2004; Soares \& Machado, 2007; Almeida et al., 2008). Nos 
experimentos realizados é observado que nem todas as amostras promoveram ativação das enzimas.

Pode-se inferir que o extrato e frações obtidos das folhas de Bauhinia ungulata L. apresentam efeitos fitotóxico ao interferir na divisão celular com predomínio de efeitos inibitórios sobre as diferentes fases da mitose em células meristemáticas nas raízes das plântulas de alface que levam a diminuição do crescimento das mesmas.

Efeito inibitório expressivo sobre as diferentes fases da mitose foi observado com a FAE. Com relação à atividade enzimática houve predomínio de aumento da atividade para a alfa amilase. Estímulo, inibição ou nenhuma alteração com relação às atividades das peroxidases, catalases e polifenol oxidases foram observados dependendo da amostra e concentração.

Os resultados obtidos indicam potencial fitotóxico do extrato etanólico e das frações do mesmo, obtidos a partir de folhas de B. ungulata, devido à presença de compostos com atividade inibidora ou estimulatória sobre o índice de mitoses em células meristemáticas das raízes e na alteração da produção das enzimas alfa amilase, peroxidase, catalase e polifenol oxidase em plantas de alface.

\section{AGRADECIMENTOS}

A Capes pelo suporte financeiro e bolsas de doutorado, a Sra. Geciane Mirian da Silva pelo auxílio com a coleta do material e ao Herbário da Universidade Federal de Mato Grosso do Sul pela identificação da espécie.

\section{REFERÊNCIAS}

ADAM, F.I.M; EL-ASHRY, Z.M. Evaluation of genotoxicity of 4-n-nonylphenol using Vicia faba L. Journal of Biological Sciences, v.10, n.4, p.368-372, 2010.

$\mathrm{AEBI}, \mathrm{H}$. Catalase in vitro. Methods in Enzymology, v.105, p.121-126, 1984.

ALMEIDA, G.D. et al. Estresse oxidativo em células vegetais mediante aleloquímicos. Revista da Faculdads Nacional de Agronomia, v.61, n.1, p.4237-4247, 2008.

ANDERSON, M.D. et al. Changes in isozyme profiles of catalase, peroxidase, and glutathione reductase during acclimation to chilling in mesocotylus of maize seedlings. Plant Physiology, v.109, n.4, p.1247-1257, 1995.

AOAC. Association of Official Agricultural Chemists. Official methods of analysis. 10.ed. Washington: Editorial Board, 1965. 656p.

BALDO, M. Aspectos histológicos e bioquímicos da indução de resistência em feijoeiro e atividade antifúngica por derivados de Pycnoporus sanguineus. 2008. 83p. Dissertação (Mestrado - Área de Concentração em Agronomia) - Centro de Ciências Agrárias, Universidade Estadual do Oeste do Paraná,
Marechal Cândido Rondon.

BRACHT, A. et al. Enzimas. In: BRACHT, A.; ISHIIIWAMOTO, E.L. Métodos de laboratório em Bioquímica. v.1, Maringá: Manole, 2003. p.103-137.

CAMPOS, A.D. et al. Atividade de peroxidase e polifenoloxidase na resistência do feijão à antracnose. Revista de Agropecuária Brasileira, v.19, p.637-643, 2004.

CARVALHO, N.M.; NAKAGAWA, J. Sementes: ciência, tecnologia e produção. 3. ed. Campinas: Fundação Cargill, 1988. 424 p.

CAVALCANTI, L.S. et al. Aspectos bioquímicos e moleculares da resistência induzida. In: CAVALCANTI, L.S. et al. Indução de resistência em plantas a patógenos e insetos. Piracicaba: FEALQ, 2005, p.81-124.

DING, L. et al. Regulation of cell division and growth in roots of Lactuca sativa L. seedlings by the entkaurene diterpenoid rabdosin B. Journal of Chemical Ecology, v.36, p.553-563, 2010.

DUANGMAL, K.; APENTEN, R.K.O. A comparative study of polyphenoloxidases from taro (Colocasia esculenta) and potato (Solanun tuberosum var. romano). Food Chemistry, v. 64, p. 351-359, 1999.

EINHELLIG, F. A. Mechanisms and modes of action of allelochemicals. In: PUTNAM, A. R; TANG, C. H.-S. (ed.). The Science of Allelopathy. Nova York: John Wiley and Sons, 1986. p.171-188.

GONZÁLEZ, P.S. et al. Evaluation of phenol detoxification by Brassica napus hairy roots, using Allium cepa test. Environmental Science and Pollution Research, v.18, n.1, p.482-491, 2011.

JACOBSEN, J.V. et al. Water stress enhances expression of an alpha-amylase gene in barley leaves. Plant Physiology, v.80, p.350, 1986.

KATO-NOGUCHI, H. et al. Phytotoxic substances with allelopathic activity may be central to the strong invasive potential of Brachiaria brizantha. Journal of Plant Physiology, v.171, n.7, p.525-530, 2014.

LEME, D.M.; MARIN-MORALES, M.A. Allium cepa Test in environmental monitoring: a review on its application. Mutation Research, v.682, p.71-81, 2009.

MACÍAS, F.A. et al. Search for a standard phytotoxic biossay for allelochemicals. Selection of standard target species. Journal of Agricultural and Food Chemistry, v.48, p.2512-2521, 2000.

MAIANETO, M. et al. Flavonoids and alkaloids from leaves of Bauhinia ungulata L. Biochemical Systematics and Ecology, v.36, p.227-229, 2008.

MAULI, M. M. et al. Alelopatia de Leucena sobre soja e plantas invasoras. Semina: Ciências Agrárias, v.30, p.55-62, 2009.

MELOS J.L.R.; HONDA N.K. Constituintes químicos e avaliação do potencial alelopático de Adiantum tetraphyllum Humb. \& Bonpl. ex. Willd (Pteridaceae). Quimica Nova, v.30, p.292-297, 2007.

MORAIS, S.M. et al. Plantas medicinais usadas pelos índios Tapebas do Ceará. Brazilian Journal of Pharmacognosy, v.15, p.169-177, 2005.

MOURÃO JÚNIOR, M.; SOUZA FILHO, A.P.S. Differences in Allelopathic Activity Patterns in Leguminosae. Planta Daninha, v.28, p.939-951, 2010. 
PAULA, C.S. et al. Atividade alelopática do extrato e frações das folhas de Dasyphyllum tomentosum (Spreng.) Cabrera. Revista de Ciências Farmacêuticas Básica e Aplicada, v.35, n.1, p.47-52, 2014.

PERGO, E.M., ISHII-IWAMOTO, E.L. Changes in energy metabolism and antioxidant defense systems during seed germination of the weed species Ipomoea triloba $\mathrm{L}$. and the responses to allelochemicals. Journal of Chemical Ecology, v.37, p.500-513, 2011.

PUTTER, J. Peroxidases. In Bergmeyer H.U. Methods of Enzymatic Analysis. $2^{\text {nd }}$. Weinhan: Verlag Chemie, 1974, p.685-690.

REIGOSA, M.J. et al. Ecophysiological approach in allelopathy. Critical Reviews in Plant Sciences, v.18, 1999. p.577-608.

REIGOSA, M. J. et al. Cell cycle analyses for understanding growth inhibition, In: Reigosa, M.J.; Pedrol, N.; González, L. (Ed). Allelopathy: A Physiological Process with Ecological Implications. Netherlands: Springer, 2006, p.141-156.

RIAL, C. et al. Phytotoxicity of Cardoon (Cynara cardunculus) Allelochemicals on Standard Target Species and Weeds. Journal of Agricultural and food chemistry, v.62, n.28, p.6699-6706, 2014.
RIEDLE-BAUER, M. Role of Reactive Oxygen Species and Antioxidant Enzymes in Systemic Virus Infections of Plants. Journal of Phytopathology, v.148, p.297302, 2000.

SOARES, A.M.S.; MACHADO, O.L.T. Defesa de plantas: sinalização química e espécies reativas de oxigênio. Revista Trópica, v.1, p.9-18, 2007.

TREVISAN, R.R. et al. Avaliação da atividade fitotóxica com enfoque alelopático do extrato das cascas de Celtis iguanaea (Jacq.) Sargent Ulmaceae e purificação de dois triterpenos. Revista Brasileira de Plantas Medicinais, v.14, p.494-499, 2012.

VIECELLI, C.A. et al. Indução de resistência em feijoeiro a mancha angular por extratos de micélio de Pycnoporus sanguineus. Summa Phytopathology, v.36, p.73-80, 2010.

ZERAIK, A.E. et al. Desenvolvimento de um spot test para o monitoramento da atividade da peroxidase em um procedimento de purificação. Química Nova, v.31, p.731-734, 2008.

WANG, Q. et al. Allelopathic activity and chemical constituents of walnut (Juglans regia) leaf litter in walnutwinter vegetable agroforestry system. Natural Product Research, v.1, p.1-4, 2014. 